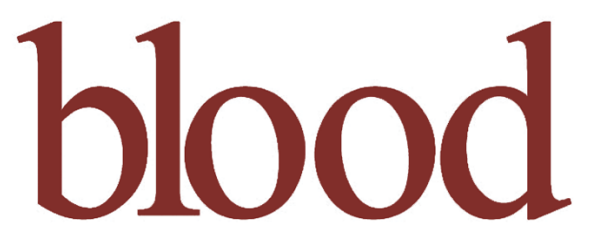

2002 100: 2499-2505

Prepublished online Jun 14, 2002;

doi:10.1182/blood-2002-03-0812

\title{
P2X1-mediated activation of extracellular signal-regulated kinase 2 contributes to platelet secretion and aggregation induced by collagen
}

Cécile Oury, Emese Toth-Zsamboki, Jos Vermylen and Marc F. Hoylaerts

Updated information and services can be found at:

http://bloodjournal.hematologylibrary.org/cgi/content/full/100/7/2499

Articles on similar topics may be found in the following Blood collections:

Signal Transduction (1930 articles)

Hemostasis, Thrombosis, and Vascular Biology (2445 articles)

Information about reproducing this article in parts or in its entirety may be found online at:

http://bloodjournal.hematologylibrary.org/misc/rights.dt|\#repub_requests

Information about ordering reprints may be found online at:

http://bloodjournal.hematologylibrary.org/misc/rights.dtl\#reprints

Information about subscriptions and ASH membership may be found online at:

http://bloodjournal.hematologylibrary.org/subscriptions/index.dtI

Blood (print ISSN 0006-4971, online ISSN 1528-0020), is published semimonthly by the American Society of Hematology, 1900 M St, NW, Suite 200, Washington DC 20036.

Copyright 2007 by The American Society of Hematology; all rights reserved.

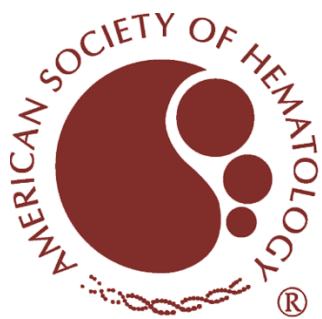




\section{$\mathrm{P} 2 \mathrm{X}_{1}$-mediated activation of extracellular signal-regulated kinase 2 contributes to platelet secretion and aggregation induced by collagen}

Cécile Oury, Emese Toth-Zsamboki, Jos Vermylen, and Marc F. Hoylaerts

\begin{abstract}
Adenosine triphosphate (ATP) and its stable analog, $\alpha, \beta-$ methylene ATP, activate the platelet $\mathbf{P} 2 \mathrm{X}_{1}$ ion channel, causing a rapid $\mathrm{Ca}^{++}$influx. Here, we show that, in washed apyrase-treated platelets, $\alpha, \beta$-methylene ATP elicits reversible extracellular signal-regulated kinase 2 (ERK2) phosphorylation through a $\mathrm{Ca}^{++}$and protein kinase C-dependent pathway. In contrast, high-performance liquid chromatography-purified adenosine diphosphate (ADP) did not trigger ERK2 phosphorylation. $\alpha, \beta$-Methylene ATP also activated the ERK2 pathway in $\mathrm{P}_{2} \mathrm{X}_{1}$-transfected HEK293 cells but not in cells expressing mutated $\mathrm{P}_{2} \mathrm{X}_{1}$ delL nonfunctional channels. Because ATP released from the dense granules during platelet activation
\end{abstract}

contributes to platelet aggregation elicited by low doses of collagen, and because collagen causes ERK2 phosphorylation, we have investigated the role of $\mathrm{P}^{2} \mathrm{X}_{1}$-mediated ERK2 activation in these platelet responses. We found that the antagonism of $\mathrm{P} 2 \mathrm{X}_{1}$ with ADP or desensitization of this ion channel with $\alpha, \beta$ methylene ATP both resulted in impaired ERK2 phosphorylation, ATP secretion, and platelet aggregation induced by low concentrations of collagen ( $\leq 1 \mu \mathrm{g} / \mathrm{mL}$ ) without affecting the minor early dense granule release. Selective MEK1/2 inhibition by $\mathrm{U}-0126$ and $\mathrm{Ca}^{++}$chelation with EGTA (ethyleneglycoltetraacetic acid) behaved similarly, whereas the PKC inhibitor GF109203-X totally prevented collagen- induced secretion and ERK2 activation. In contrast, when elicited by high collagen concentrations $(2 \mu \mathrm{g} / \mathrm{mL})$, platelet aggregation and secretion no longer depended on $\mathrm{P}_{2} \mathrm{X}_{1}$ or ERK2 activation, as shown by the lack of their inhibition by $\alpha, \beta$-methylene ATP or U-0126. We thus conclude that mild platelet stimulation with collagen rapidly releases ATP, which activates the P2X 1 -PKC-ERK2 pathway. This process enhances further degranulation of the collagen-primed granules allowing platelet aggregation to be completed. (Blood. 2002;100:2499-2505)

(C) 2002 by The American Society of Hematology

\section{Introduction}

Present in very high concentrations in the platelet-dense granules, both adenosine diphosphate (ADP) and adenosine triphosphate (ATP) are secreted during platelet activation. ${ }^{1}$ ADP has long been recognized as an important activator of platelets, playing an essential role in enhancing secretion, and stabilizing platelet aggregates induced by other agonists. ${ }^{2}$ ADP activates 2 receptors (for a review, see $\mathrm{Gachet}^{3}$ ); $\mathrm{P} 2 \mathrm{Y}_{1}$, coupled to a $\mathrm{Gq}$ protein, is responsible for shape change and initiation of platelet aggregation, and $\mathrm{P}_{2} \mathrm{Y}_{12}{ }^{4}$ a target for specific antithrombotic drugs, leads to adenylate cyclase inhibition through a Gi protein and promotes the completion and amplification of platelet responses. Recently, ATP was found to be the agonist of the ionotropic $\mathrm{P} 2 \mathrm{X}_{1}$ receptor, causing a rapid influx of $\mathrm{Ca}^{++} .5,6$ Because platelet studies have mainly been performed at low extracellular $\mathrm{Ca}^{++}$concentrations in citrated plasma, but also due to the difficulties in preserving $\mathrm{P}_{2} \mathrm{X}_{1}$ functionality during platelet handling because of its fast desensitization by spontaneously released $\mathrm{ATP},{ }^{7}$ the function of the platelet $\mathrm{P} 2 \mathrm{X}_{1}$ ion channel only recently started to be unraveled. Two studies described the ability of the $\mathrm{P} 2 \mathrm{X}_{1}$ selective agonists, $\alpha, \beta$ methylene ATP $(\alpha, \beta$-meATP) and L- $\beta, \gamma$-methylene ATP, to produce a reversible platelet shape change. ${ }^{8,9}$ We also provided evidence for a role of the ion channel in platelet shape change and aggregation induced by low doses of collagen. ${ }^{9}$

$\mathrm{P} 2 \mathrm{X}_{1}$ belongs to an emerging family of ionotropic receptors that are involved in many physiologic processes..$^{10}$ The ionotropic P2X receptors regulate intracellular $\mathrm{Ca}^{++}$levels through the ligandstimulated increase in calcium permeability. However, how these receptors are linked to intracellular signaling pathways subserving their biologic actions still is poorly understood. In PC12 cells, Swanson and coworkers ${ }^{11}$ have shown that $\mathrm{P} 2 \mathrm{X}_{2}$ mediates the activation of the extracellular signal-regulated kinase (ERK1/2) members of the mitogen-activated protein kinase (MAPK) family of serine/threonine kinases ${ }^{12}$ via a protein kinase $\mathrm{C}(\mathrm{PKC})-$ and proline-rich tyrosine kinase 2 (PYK2)-dependent pathway.

The prototype ERK pathway consists of a cascade of protein kinases, Raf1, the MAPK kinase MEK1, and ERK1/2, which sequentially activate a downstream kinase. In platelets, ERKs have been shown to be activated after stimulation by thrombin, ${ }^{13}$ collagen, ${ }^{14}$ or phorbol esters ${ }^{15}$ as well as to play a role during store-mediated $\mathrm{Ca}^{++}$entry. ${ }^{16}$ ERK2 was also shown to be downregulated by $\alpha_{\mathrm{II}} \beta_{3}$ engaged in ligand binding or aggregation, ${ }^{17}$ and
From the Center for Molecular and Vascular Biology, University of Leuven, Belgium.

Submitted March 18, 2002; accepted May 15, 2002. Prepublished online as Blood First Edition Paper, June 14, 2002; DOI 10.1182/blood-2002-03-0812.

Support was obtained from the bilateral scientific and technological cooperation between Flanders and Hungary (BIL00/12) and from the Fonds Wetenschappelijk Onderzoek Vlaanderen (FWO) project G 0376.01. E.T.Z. is recipient of a doctoral KU Leuven scholarship. C.O. is holder of a postdoctoral research mandate of the FWO.
Reprints: Marc F. Hoylaerts, Center for Molecular and Vascular Biology, University of Leuven, Herestraat 49, B-3000 Leuven, Belgium; e-mail: marc.hoylaerts@med.kuleuven.ac.be.

The publication costs of this article were defrayed in part by page charge payment. Therefore, and solely to indicate this fact, this article is hereby marked "advertisement" in accordance with 18 U.S.C. section 1734.

(C) 2002 by The American Society of Hematology 
a recent study indicated that von Willebrand factor binding to glycoprotein Ib-IX leads to $\alpha_{\mathrm{IIb}} \beta_{3}$ activation via ERK2. ${ }^{18}$ However, the upstream effectors and the downstream targets of the platelet ERK signaling pathway remain largely uncharacterized.

In this study, we found that $\alpha, \beta$-meATP elicits reversible ERK2 phosphorylation through a $\mathrm{Ca}^{++}$- and $\mathrm{PKC}$-dependent pathway. We showed that the minor early ATP secretion evoked by low concentrations of collagen activates the $\mathrm{P} 2 \mathrm{X}_{1}$-mediated $\mathrm{Ca}^{++}$ influx leading to ERK2 phosphorylation. The P2X $\mathrm{X}_{1}$-PKC-ERK2 pathway plays a role in amplifying dense granule release, an event needed for completion of platelet aggregation on mild stimulation with collagen.

\section{Materials and methods}

\section{Materials}

ADP, adenosine $5^{\prime}$ - $(\alpha, \beta$-methylene) triphosphate $(\alpha, \beta$-meATP), adenosine $2^{\prime}$-phosphate $5^{\prime}$-phosphate (A2P5P), and indomethacin were from Sigma (St Louis, MO). ARC-69931MX was a gift from Astra Zeneca R+D (Charnwood, United Kingdom). ${ }^{19}$ Collagen (collagen reagent horm) was from Nycomed (Munich, Germany). U-0126 and GF109203-X were purchased from Biomol Research Laboratories (Plymouth Meeting, PA). $\mathrm{ADP}$ and $\alpha, \beta$-meATP were purified by high-performance liquid chromatography (HPLC) on an Adsorbosphere HS C18, $7 \mu \mathrm{m}, 250 \times 4.6 \mathrm{~mm}$, column (Alltech, Bad Segeberg, Germany) as described. ${ }^{9}$

\section{Preparation of hirudinized PRP and washed platelets}

Blood freshly drawn from healthy donors was mixed with $20 \mu \mathrm{g} / \mathrm{mL}$ hirudin in saline, centrifuged at $150 \mathrm{~g}$ for 15 minutes, and the platelet-rich plasma (PRP) was collected. The platelet counts were adjusted to $2.5 \times 10^{5}$ platelets $/ \mu \mathrm{L}$ with autologous platelet-poor plasma (PPP). For the preparation of washed platelets, blood was collected on acid-citrate-dextrose (ACD; $93 \mathrm{mM}$ sodium citrate, $7 \mathrm{mM}$ citric acid, $0.14 \mathrm{mM}$ dextrose, $\mathrm{pH}$ 6.5) in a volume ratio of ACD to blood of 1:6, and centrifuged for 15 minutes at $150 \mathrm{~g}$ in the presence of apyrase $(1 \mathrm{U} / \mathrm{mL}$, grade I; Sigma), when indicated. The PRP was then diluted 3-fold in apyrase-containing ACD, and centrifuged for 10 minutes at $800 \mathrm{~g}$. The platelet pellet was then resuspended in Tyrode buffer $(137 \mathrm{mM} \mathrm{NaCl}, 12 \mathrm{mM} \mathrm{NaHCO}, 2 \mathrm{mM} \mathrm{KCl}, 0.34 \mathrm{mM}$ $\mathrm{Na}_{2} \mathrm{HPO}_{4}, 1 \mathrm{mM} \mathrm{MgCl}, 5.5 \mathrm{mM}$ glucose, and $5 \mathrm{mM}$ HEPES $[N-2-$ hydroxyethylpiperazine- $N^{\prime}$-2-ethanesulfonic acid], $\mathrm{pH}$ 7.3) containing $0.35 \%$ human serum albumin and $1 \mathrm{U} / \mathrm{mL}$ apyrase, at a density of $2.0 \times 10^{5}$ platelets $/ \mu \mathrm{L}$. $\mathrm{CaCl}_{2}(2 \mathrm{mM})$ was added prior to the agonists unless indicated differently.

\section{Platelet aggregation and ATP secretion analyses}

Light transmission during collagen-induced platelet aggregation was recorded in hirudinized PRP or apyrase-treated washed platelets on a Chrono-Log Aggregometer (Havertown, PA). ATP secretion was monitored in hirudinized PRP or in washed platelets in parallel with platelet aggregation by adding firefly luciferase and luciferin and comparing the luminescence generated by platelet ATP release or by an ATP standard (Kordia, Leiden, The Netherlands). $\mathrm{P} 2 \mathrm{X}_{1}$ desensitization occurs within a few milliseconds; therefore desensitization could be accomplished by adding $\alpha, \beta$-meATP $(0.5 \mu \mathrm{M})$ simultaneously with collagen to prevent released ATP from activating the ion channel. ${ }^{7} \mathrm{P}^{2} \mathrm{X}_{1}$ antagonism was achieved by adding ADP $(0.5 \mu \mathrm{M}) 1$ minute prior to collagen. ${ }^{9}$ The MEK1/2 inhibitor U-0126, the PKC inhibitor GF109203-X, or vehicle was added 2 minutes prior to collagen. EGTA (ethylene glycol tetraacetic acid) was added 5 minutes prior to collagen. At least 3 independent experiments were performed on platelets from different individuals. The data are represented as the mean \pm SEM. Statistical analysis of the data were made using nonpaired Student $t$ test.

\section{Phospho-ERK1/2 detection}

Serum-starved stable $\mathrm{P}_{2} \mathrm{X}_{1^{-}}$and $\mathrm{P} 2 \mathrm{X}_{1}$ delL-expressing HEK293 cells $\left(0.5 \times 10^{5}\right.$ cells $),{ }^{20}$ or stirred washed platelets $(0.3-\mathrm{mL}$ aliquots $)$ that had been treated with apyrase $(1 \mathrm{U} / \mathrm{mL})$ for 30 minutes, were stimulated with agonists at $37^{\circ} \mathrm{C}$. The reaction was stopped by the addition of sodium dodecyl sulfate (SDS) sample buffer $(62.5 \mathrm{mM}$ Tris-HCl, pH 6.8, $2 \%$ SDS, $10 \%$ glycerol, $50 \mathrm{mM}$ dithiothreitol, $0.1 \%$ bromophenol blue). Then $40-\mu \mathrm{L}$ sample aliquots were loaded on SDS-polyacrylamide gel electrophoresis (SDS-PAGE; 10\%) and subjected to Western blotting using the PhosphoPlus p44/42 MAP kinase antibody kit (New England Biolabs, Hitchin, United Kingdom) according to the instructions of the manufacturer. The data are representative of at least 3 independent experiments performed on different cell extracts or on platelets from different individuals.

\section{Results}

P2X 1 stimulation selectively causes $\mathrm{Ca}^{++}$- and PKC-dependent ERK2 activation

We have investigated the intracellular signaling pathways selectively activated through $\mathrm{P} 2 \mathrm{X}_{1}$ and that could subserve the role of this ion channel during platelet activation. We found that in apyrase-treated washed platelets, $\alpha, \beta$-meATP $(2 \mu \mathrm{M})$ caused rapid and reversible ERK2 phosphorylation (about 5-fold stimulation), reaching a maximum at 2 minutes and disappearing after 10 minutes (Figure 1A). Figure 1B shows the dose response to this agonist, which is in agreement with the previously described concentrations for $\alpha, \beta$-meATP-induced platelet shape change. ${ }^{9}$ The $\alpha, \beta$-meATP-elicited ERK2 phosphorylation was fully inhibited by GF109203-X, an inhibitor of the $\alpha, \beta, \gamma$, and $\epsilon$ isoforms of PKC and by the highly specific MEK inhibitor, U-0126 (Figure 2A). ERK2 phosphorylation also required extracellular $\mathrm{Ca}^{++}$ because it no longer occurred in the presence of EGTA (Figure 2B) and was almost absent when no extracellular $\mathrm{Ca}^{++}$was added (data not shown). HPLC-purified ADP (from 0.5 up to $20 \mu \mathrm{M}$ ) was unable to induce ERK2 phosphorylation at any time point (Figure 2C). These data revealed that, in platelets, the $\mathrm{P} 2 \mathrm{X}_{1}$-mediated $\mathrm{Ca}^{++}$ influx activates a PKC-dependent ERK2 signaling pathway.

A

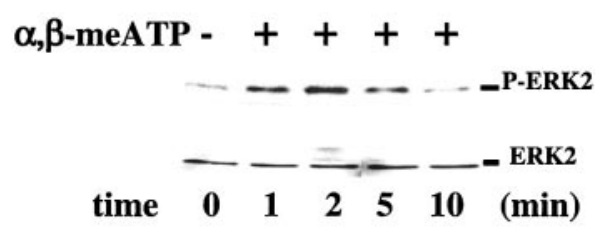

B

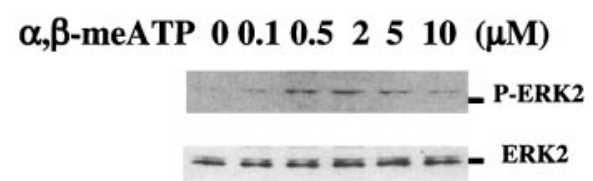

Figure 1. $\mathrm{P} 2 \mathrm{X}_{1}$ mediates ERK2 phosphorylation in platelets. Western blot analyses of $\alpha, \beta$-meATP-induced ERK2 phosphorylation in apyrase-treated washed platelets using Phospho-ERK1/2 MAP kinase (P-ERK2) and control MAP kinase (ERK2, lower panels) antibodies. (A) Time course of $2 \mu \mathrm{M} \alpha, \beta$-meATP-induced ERK2 phosphorylation. (B) Platelets were stimulated with increasing concentrations of $\alpha, \beta$-meATP for 2 minutes. 
A

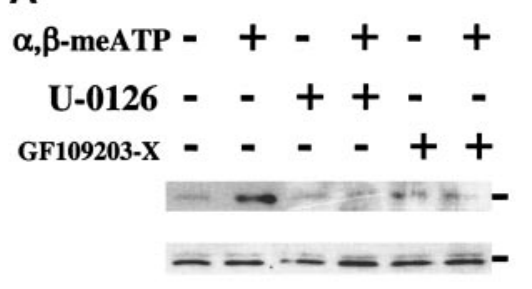

B
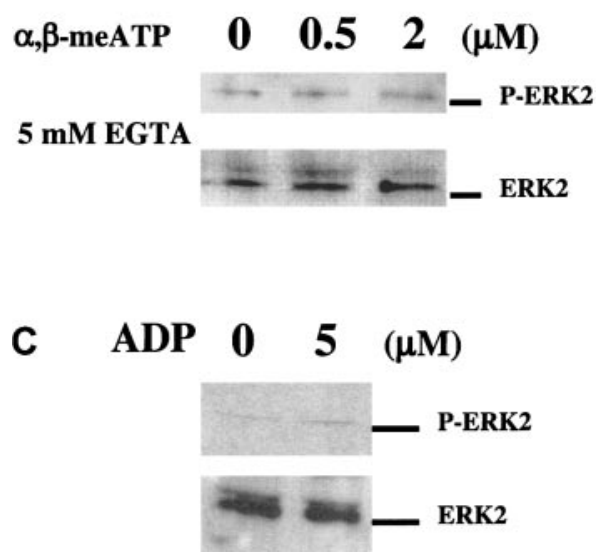

Figure 2. The $\mathbf{P} 2 \mathrm{X}_{1}$-mediated ERK2 phosphorylation depends on $\mathrm{Ca}^{++}$and PKC. Western blot analyses of $\alpha, \beta$-meATP-induced ERK2 activation in apyrasetreated washed platelets using the same antibodies as in Figure 1. (A) $\alpha, \beta$-meATPinduced ERK2 activation was analyzed after 2 minutes with or without 2 minutes of preincubation with the MEK inhibitor U-0126 (1 $\mu$ M) or the PKC inhibitor GF109203-X $(10 \mu \mathrm{M})$, as indicated. (B) Dose response to $\alpha, \beta$-meATP in the presence of $5 \mathrm{mM}$ EGTA. (C) Platelets were stimulated for 2 minutes with $5 \mu M$ ADP.

\section{The dominant-negative $\mathrm{P}_{2} \mathrm{X}_{1}$ delL mutant is unable to} activate ERK2

We have previously identified and characterized a nonfunctional dominant-negative mutant of $\mathrm{P}_{2} \mathrm{X}_{1}\left(\mathrm{P} 2 \mathrm{X}_{1}\right.$ delL) ${ }^{20}$ To further demonstrate the ability of the $\mathrm{P} 2 \mathrm{X}_{1}$-elicited $\mathrm{Ca}^{++}$influx to selectively activate the ERK2 pathway, apyrase-treated HEK293 cells stably expressing either the normal $\mathrm{P} 2 \mathrm{X}_{1}$ protein $\left(\mathrm{P} 2 \mathrm{X}_{1} \mathrm{wt}\right)$ or $\mathrm{P} 2 \mathrm{X}_{1}$ delL were stimulated with $\alpha, \beta$-meATP for 2 minutes before analyzing ERK phosphorylation. $\alpha, \beta$-meATP induced phosphorylation of ERK1/2 in $\mathrm{P} 2 \mathrm{X}_{1}$ wt-expressing cells but not in cells expressing the nonfunctional $\mathrm{P} 2 \mathrm{X}_{1}$ delL channels (Figure 3 ). The nontransfected cells did not respond to $\alpha, \beta$-meATP (data not shown). These results thus established a direct correlation between the presence of functional $\mathrm{P} 2 \mathrm{X}_{1}$ channels, triggering $\mathrm{Ca}^{++}$influx, and the activation of ERK.

\section{HEK293 cells}

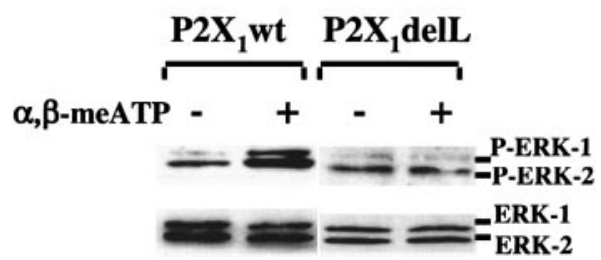

Figure 3. Selective P2X $\mathrm{X}_{1}$-mediated ERK2 phosphorylation in transfected HEK293 cells. Western blot analyses of ERK1/2 phosphorylation in apyrase-treated HEK293 cells, stably expressing normal $\mathrm{P}_{2} \mathrm{X}_{1}\left(\mathrm{P}_{2} \mathrm{X}_{1} \mathrm{wt}\right)$ or its dominant-negative $\mathrm{P} 2 \mathrm{X}_{1}$ dell mutant. ERK1/2 activation was induced with $100 \mu \mathrm{M} \alpha, \beta$-meATP in the presence of 2 $\mathrm{mM} \mathrm{CaCl}_{2}$.
Inhibition of $\mathrm{P}_{2} \mathrm{X}_{1}$ or ERK2 activation impairs dense granule release in platelets stimulated with low concentrations of collagen

Collagen-induced platelet aggregation largely depends on secretion, and the importance of $\mathrm{ADP}$, acting at $\mathrm{P}_{2} \mathrm{Y}_{1}$ and $\mathrm{P} 2 \mathrm{Y}_{12}$, is well documented. ${ }^{3}$ We recently reported that $\mathrm{P} 2 \mathrm{X}_{1}$, through secreted ATP, is also required for platelet aggregation elicited by low doses of collagen. ${ }^{9}$ We wanted to determine whether the $\mathrm{P} 2 \mathrm{X}_{1}-\mathrm{PKC}$ ERK2 signaling pathway plays a role in this process. Therefore, we have recorded ATP secretion in parallel with platelet aggregation and analyzed the effects of $\mathrm{P}_{2} \mathrm{X}_{1}$ desensitization and MEK inhibition on these platelet responses. These recordings were performed in hirudinized PRP to maintain physiologic $\mathrm{Ca}^{++}$ concentrations and preserve enough $\mathrm{P} 2 \mathrm{X}_{1}$ functionality for the purpose of the experiment. Despite the fact that $\alpha, \beta$-meATP could not induce ATP release by itself, these analyses revealed that both $\mathrm{P}_{2} \mathrm{X}_{1}$ desensitization with $\alpha, \beta$-meATP and MEK inhibition by U-0126 potently impaired ATP release triggered by low doses of collagen $(0.4-1 \mu \mathrm{g} / \mathrm{mL})$. Collagen $(0.5 \mu \mathrm{g} / \mathrm{mL})$ induced $4.29 \pm 0.22$ $\mu \mathrm{M}$ ATP release (Figure 4 ), which was reduced to $0.14 \pm 0.08 \mu \mathrm{M}$ (n $=7, P<.0001)$ in the presence of $\alpha, \beta$-meATP (Figure 4 ), and

\section{$0.5 \mu \mathrm{g} / \mathrm{mL}$ collagen}
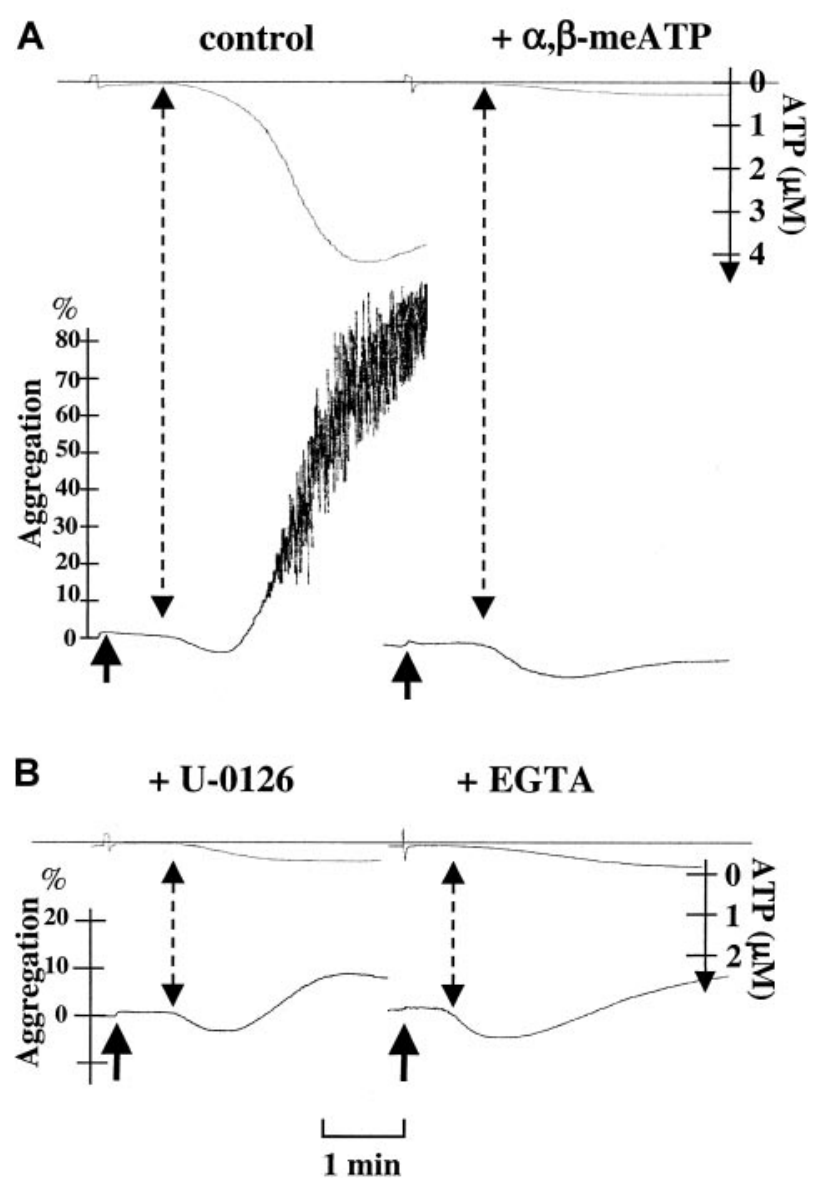

Figure 4. Role of $\mathrm{P} 2 \mathrm{X}_{1}$-mediated ERK2 activation in platelet ATP secretion and aggregation induced by low concentrations of collagen. Parallel recordings of light transmission (\%) and ATP secretion $(\mu \mathrm{M})$ in hirudinized PRP during platelet stimulation with $0.5 \mu \mathrm{g} / \mathrm{mL}$ collagen alone (control), in the presence of $0.5 \mu \mathrm{M}$ $\alpha, \beta$-meATP, after a 2-minute preincubation with $1 \mu \mathrm{M} \cup 0126$, or in the presence of 10 mM EGTA, as indicated. Arrows represent the time of application of collagen. Dashed arrows indicate the moment of initial detection of ATP during platelet aggregation. Percentages of light transmission, the concentrations of ATP released, and the time bar are included. 
From www.bloodjournal.org by on September 5, 2008. For personal use only.

to $0.35 \pm 0.08 \mu \mathrm{M}(\mathrm{n}=4, P<.0001)$ by $\mathrm{U}-0126$ (Figure 4$)$. Because in the $\mathrm{Ca}^{++}$-rich environment of hirudinized PRP, indomethacin only slightly inhibited the collagen-induced platelet aggregation (data not shown), no major role in aggregation is attributed to thromboxane $\mathrm{A}_{2}$. Therefore, the inhibition of platelet aggregation by $\mathrm{U}-0126$ is not due to nonselective inhibition of cyclooxygenase..$^{21}$ Consistent with an event requiring $\mathrm{Ca}^{++}$influx through $\mathrm{P}_{2} \mathrm{X}_{1}$, ATP secretion was similarly inhibited in the presence of the $\mathrm{Ca}^{++}$chelator EGTA $(0.56 \pm 0.11 \mu \mathrm{M}, \mathrm{n}=3$; Figure 4). In contrast, neither $\alpha, \beta$-meATP nor U-0126 affected platelet ATP secretion and aggregation evoked by higher concentrations of collagen $(2 \mu \mathrm{g} / \mathrm{mL}$; data not shown); likewise, EGTA only slightly impaired ATP secretion induced by $2 \mu \mathrm{g} / \mathrm{mL}$ collagen (data not shown). These data thus suggest an essential role for the $\mathrm{P} 2 \mathrm{X}_{1}$-PKC-ERK2 signaling pathway in enhancing dense granule release and completing platelet aggregation initiated by low doses of collagen.

\section{The P2X $\mathrm{X}_{1}$-PKC-ERK2 signaling pathway is not involved in the early collagen-induced secretion}

Platelets stimulated with collagen release ATP before the onset of shape change 22 (Figure 4$)$. This early release was totally blocked by

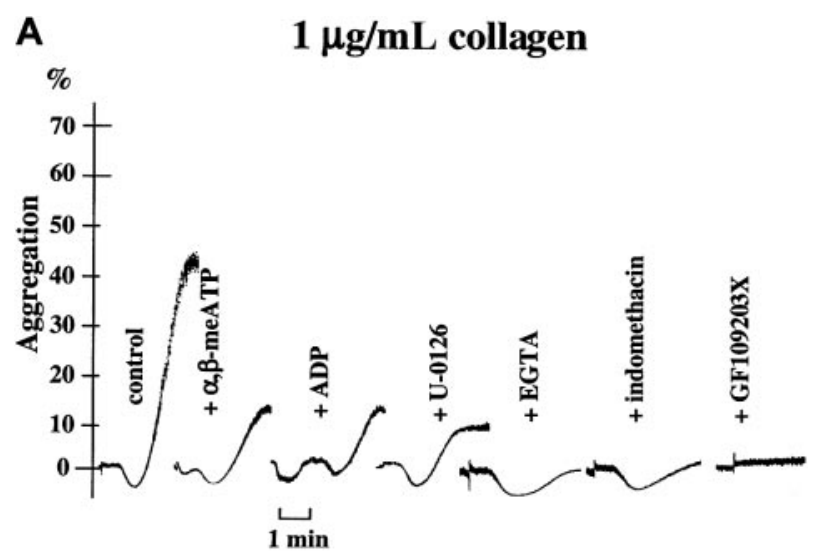

B

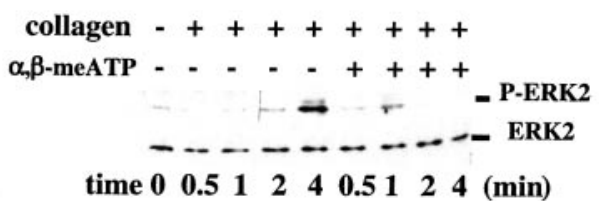

C

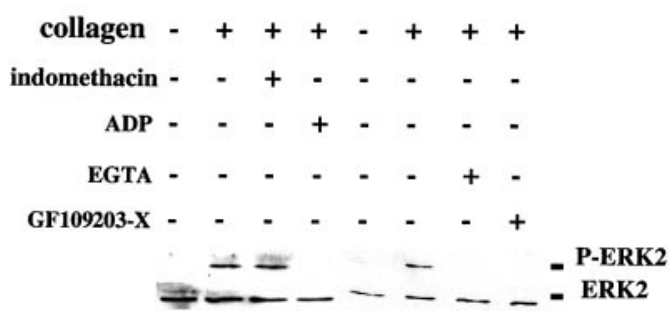

Figure 5. Activation of ERK2 at low concentrations of collagen depends on P2 $\mathrm{X}_{1}$; correlation between ERK2 phosphorylation and platelet aggregation. (A) Light transmission (\%) recordings in apyrase-treated washed platelets stimulated with collagen $(1 \mu \mathrm{g} / \mathrm{mL})$ alone (control), in the presence of $0.5 \mu \mathrm{M} \alpha, \beta$-meATP, or after preincubation with $0.5 \mu \mathrm{M}$ ADP, $1 \mu \mathrm{M}$ U-0126, $5 \mathrm{mM}$ EGTA, $10 \mu \mathrm{M}$ indomethacin, or $10 \mu \mathrm{M}$ GF109203-X, as indicated. Time bar is included. (B) Parallel Western blot analyses of ERK2 phosphorylation in these platelet samples. The time course of ERK2 phosphorylation induced by $1 \mu \mathrm{g} / \mathrm{mL}$ collagen alone or in the presence of 0.5 $\mu \mathrm{M} \alpha, \beta$-meATP is shown. (C) The ERK2 phosphorylation detected in platelets stimulated with the same concentration of collagen for 4 minutes in the presence or absence of $\alpha, \beta$-meATP, ADP, EGTA, GF109203-X, or indomethacin, as indicated. the PKC inhibitor GF109203-X (not shown), which also abolished collagen-induced platelet shape change and aggregation (Figure $5 \mathrm{~A})$. The inhibition of collagen-induced platelet shape change by the $\mathrm{P} 2 \mathrm{Y}_{1}$ receptor antagonist $\mathrm{A} 2 \mathrm{P} 5 \mathrm{P}$ was indicative of the involvement of secreted ADP (data not shown). We then wondered whether this early secretion responsible for platelet shape change precedes or depends on the activation of the $\mathrm{P} 2 \mathrm{X}_{1}$-PKC-ERK2 signaling pathway. Figure 4 revealed that neither $\alpha, \beta$-meATP nor U-0126 and EGTA were able to fully inhibit ATP release induced by collagen $(0.5 \mu \mathrm{g} / \mathrm{mL})$, and platelet shape change occurred normally. Accordingly, the ATP release induced by $0.3 \mu \mathrm{g} / \mathrm{mL}$ collagen $(0.33 \pm 0.05 \mu \mathrm{M}, \mathrm{n}=3)$, which elicited platelet shape change without causing aggregation (data not shown), was not affected by these treatments either (data not shown). These results indicate that the PKC-ERK2 pathway is not involved in the early secretion preceding platelet shape change, and further indicate that activation of this pathway is secondary to the action of the limited amount of ATP secreted during the initial response of platelets to collagen.

\section{At low-dose collagen, ERK2 phosphorylation is mediated via $\mathrm{P}_{2} \mathrm{X}_{1}$}

In platelets, collagen activates the ERK signaling pathway. ${ }^{14}$ To further investigate the contribution of $\mathrm{P} 2 \mathrm{X}_{1}$ to this pathway, we have analyzed the effect of $\mathrm{P} 2 \mathrm{X}_{1}$ desensitization on the ability of collagen to cause ERK2 phosphorylation in apyrase-treated washed platelets. Platelet aggregation was recorded in parallel. In apyrasetreated washed platelets, similarly as in hirudinized PRP, P2X desensitization with $\alpha, \beta$-meATP $(0.5 \mu \mathrm{M})$ inhibited platelet aggregation induced by low concentrations of collagen $(0.75-1 \mu \mathrm{g} / \mathrm{mL}$; Figure 5A). Western blot analyses indicated that the collagen (0.75-1 $\mu \mathrm{g} / \mathrm{mL})$-induced ERK2 phosphorylation reaches a maximum after 4 minutes following addition of the agonist (Figure 5B); the appearance of ERK2 phosphorylation at minute 2 correlated with the onset of platelet aggregation (Figure 5A,B). Interestingly, P2 $\mathrm{X}_{1}$ desensitization with $\alpha, \beta$-meATP $(0.5 \mu \mathrm{M})$, able to inhibit platelet aggregation, also led to the loss of ERK2 phosphorylation at the time where maximal activation occurred in the control (4 minutes; Figure 5A,B), even despite the fact that $\alpha, \beta$-meATP is capable of triggering ERK2 phosphorylation itself (Figure 1). We then used a low concentration of $\operatorname{ADP}(0.5 \mu \mathrm{M})$ that selectively antagonizes the ATP-induced activation of $\mathrm{P}_{2} \mathrm{X}_{1}$ as well as the $\alpha, \beta$-meATP-evoked platelet shape change ${ }^{9}$ without causing ERK2 phosphorylation (Figure 2C). Similarly as $\alpha, \beta$-meATP, ADP pretreatment prevented the collagen-induced ERK2 phosphorylation (Figure 5C) as well as platelet aggregation (Figure 5A and Oury et $\mathrm{al}^{9}$ ). These results show that the observed inhibition of ERK2 activation can be caused both by $\mathrm{P} 2 \mathrm{X}_{1}$ antagonism (ADP) and desensitization $\left(\alpha, \beta\right.$-meATP), the $2 \mathrm{P}^{2} \mathrm{X}_{1}$ neutralizing approaches leading to impaired platelet aggregation. The collagen-induced ERK2 activation and aggregation were also abolished in the presence of EGTA (Figure 5A,C), supportive of the involvement of $\mathrm{P} 2 \mathrm{X}_{1}$-mediated $\mathrm{Ca}^{++}$influx (Figure 2B). The PKC inhibitor GF109203-X that prevents platelet secretion (data not shown), shape change, and aggregation evoked by collagen (Figure 5A), and the $\alpha, \beta$-meATP-elicited ERK2 activation (Figure 2A), inhibited ERK2 activation caused by collagen, as expected (Figure 5C). The inhibition of collagen-induced ERK2 phosphorylation by U-0126 (Figure 6B) equally blocked platelet aggregation (Figure $5 \mathrm{~A})$, confirming the importance of the $\mathrm{P}_{2} \mathrm{X}_{1}$-ERK2 pathway, also when studied in apyrase-treated washed platelets. The further inhibition of U-0126-treated platelets with GF109203-X abolished platelet shape change and residual ATP secretion (data not shown), 
A
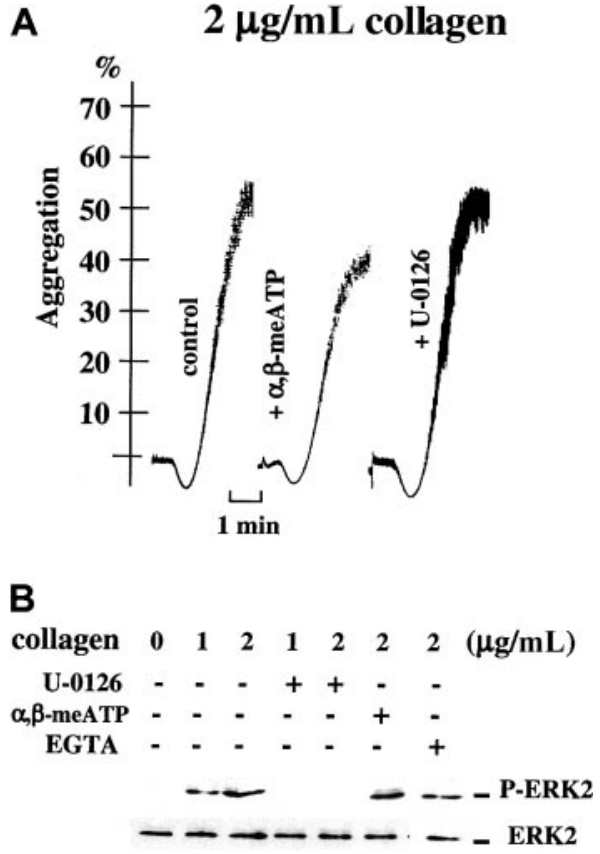

Figure 6. Platelet aggregation induced by high concentrations of collagen does not depend on the ERK2 pathway. (A) Light transmission (\%) recordings in apyrase-treated washed platelets stimulated with $2 \mu \mathrm{g} / \mathrm{mL}$ collagen alone (control), in the presence of $0.5 \mu \mathrm{M} \alpha, \beta$-meATP, or after preincubation with $1 \mu \mathrm{M} \mathrm{U}-0126$, as indicated. Time bar is included. (B) Parallel Western blot analyses of ERK2 phosphorylation in these platelet samples. ERK2 phosphorylation was induced by 1 or $2 \mu \mathrm{g} / \mathrm{mL}$ collagen for 4 minutes alone or after preincubation with $1 \mu \mathrm{MU}-0126$ or 5 mM EGTA, as indicated; ERK2 phosphorylation was also analyzed after platelet stimulation for 4 minutes with $2 \mu \mathrm{g} / \mathrm{mL}$ collagen alone or in the presence of $0.5 \mu \mathrm{M}$ $\alpha, \beta$-meATP.

confirming that the minor early dense granule release occurs independently of ERK2. Platelet aggregation was prevented by the P2 $Y_{12}$ antagonist ARC-69931MX in agreement with a role for secreted ADP (data not shown), and was also inhibited by indomethacin (Figure 5A), indicative of a contribution of synthesized thromboxane $\mathrm{A}_{2}$ during the process of aggregation of washed platelets performed in the presence of apyrase. The relative contribution of thromboxane $\mathrm{A}_{2}$ during aggregation of apyrasetreated washed platelets thus differs from that studied in hirudinized PRP. Nevertheless, indomethacin (Figure 5C) did not affect ERK2 phosphorylation, showing that thromboxane $A_{2}$ is not involved in the activation of the ERK2 pathway. Our data thus indicate that ERK2 phosphorylation induced by low doses of collagen depends on the action of secreted ATP at P2X $\mathrm{X}_{1}$, contributing to the completion of platelet aggregation.

\section{Platelet aggregation induced by high doses of collagen no longer depends on $\mathrm{P}_{2} \mathrm{X}_{1}$ and ERK2 activation}

Desensitization of $\mathrm{P} 2 \mathrm{X}_{1}$ with $\alpha, \beta$-meATP did not inhibit ERK2 phosphorylation and aggregation of washed apyrase-treated platelets in response to high concentrations of collagen $(2 \mu \mathrm{g} / \mathrm{mL}$; Figure 6A,B). Similarly, collagen-induced ERK2 activation was no longer inhibited in the presence of EGTA (Figure 6B), showing that, in agreement with the absence of inhibition by $\alpha, \beta$-meATP, no role can be attributed to $\mathrm{P} 2 \mathrm{X}_{1}$ in these conditions of strong platelet stimulation. Interestingly, total blockade of the ERK pathway by U-0126 (Figure 6B) had no effect on platelet aggregation induced by the high concentration of collagen (Figure 6A). These data thus indicate that, at high doses of collagen, platelet aggregation occurs independently of the $\mathrm{P} 2 \mathrm{X}_{1}$-ERK2 pathway. These results also show that, at high collagen concentrations, platelet aggregation and ERK2 phosphorylation can be dissociated, ERK2 no longer being involved in secretion reactions leading to platelet aggregation.

\section{Discussion}

In the present study, we have identified the ERK2 signaling pathway as an intracellular mechanism subserving the function of the ATP-gated $\mathrm{P}_{2} \mathrm{X}_{1}$ ion channel during platelet aggregation induced by low concentrations of collagen. We have shown that the P2 $\mathrm{X}_{1}$-mediated ERK2 activation is a $\mathrm{Ca}^{++}$- and PKC-dependent process needed to amplify dense granule release initiated by this agonist.

In a previous study, we provided evidence that during collageninitiated platelet activation, the early secretion of ATP results in the activation of $\mathrm{P} 2 \mathrm{X}_{1}$ acting as a positive regulator of subsequent platelet responses. ${ }^{9}$ To investigate the role of the $\mathrm{P} 2 \mathrm{X}_{1}$-PKC-ERK2 pathway in collagen-induced platelet aggregation, we took advantage of the possibility to selectively antagonize ATP-induced $\mathrm{P}_{2} \mathrm{X}_{1}$ activation with $\mathrm{ADP}^{9}$ and to prevent $\mathrm{Ca}^{++}$influx through the ion channel via chelation of extracellular $\mathrm{Ca}^{++}$by EGTA. $\alpha, \beta$-meATP was used to specifically desensitize $\mathrm{P} \mathrm{X}_{1}$ during platelet stimulation by collagen, ${ }^{7,9}$ and the total blockade of the ERK pathway was achieved by U-0126, a highly specific inhibitor of the MAPK kinases MEK1/2. It appeared that all these inhibitory strategies similarly prevented ERK2 phosphorylation, platelet-dense granule release, and aggregation induced by low doses of collagen. Our data indicate that $\mathrm{P} 2 \mathrm{X}_{1}$ and ERK2 are proximal and distal components, respectively, of a contiguous regulatory signaling pathway participating in platelet responses to collagen.

Collagen appeared to evoke the secretion of ATP (and ADP) rapidly, prior to the onset of shape change. The collagen-induced platelet shape change was found to depend on secretion, because it was inhibited by the PKC inhibitor, GF109203-X, which totally prevents secretion elicited by this agonist; shape change was also inhibited by the $\mathrm{P} 2 \mathrm{Y}_{1}$ antagonist, A2P5P. In contrast, neither EGTA nor the MEK1/2 inhibitor U-0126 affected this platelet shape change, therefore excluding a role for the P2 $\mathrm{X}_{1}$-PKC-ERK2 signaling pathway in the very early dense granule release triggered by collagen. This indicates that another PKC-dependent secretory pathway is responsible for the minor early collagen-induced secretion.

Combining these findings, in the model depicted in Figure 7, we propose a $\mathrm{P} 2 \mathrm{X}_{1}$-dependent mechanism essential for the completion of platelet aggregation induced by low doses of collagen. According to this model, platelet stimulation with low doses of collagen rapidly causes ERK2-independent minor dense granule release (step 1); ATP secreted during this early event activates the $\mathrm{P} 2 \mathrm{X}_{1}$-PKC-ERK2 pathway (step 2), which is needed to complete platelet aggregation by enhancing the release reaction from collagenprimed dense granules (step 3). The notion of dense granule priming refers to our finding that, on one hand, the minor early release induced by collagen (activation of PKC1) is insufficient to cause platelet aggregation unless the $\mathrm{P} 2 \mathrm{X}_{1}$-PKC2-ERK2 pathway is activated; on the other hand, the sole activation of the latter pathway with $\alpha, \beta$-meATP is unable to release granule contents, unless collagen has initiated the process. Activation of PKC1 triggers minor early dense granule release but does not cause direct ERK2 phosphorylation. Thus, ERK2 activation and platelet aggregation evoked by low concentrations of collagen do not occur 


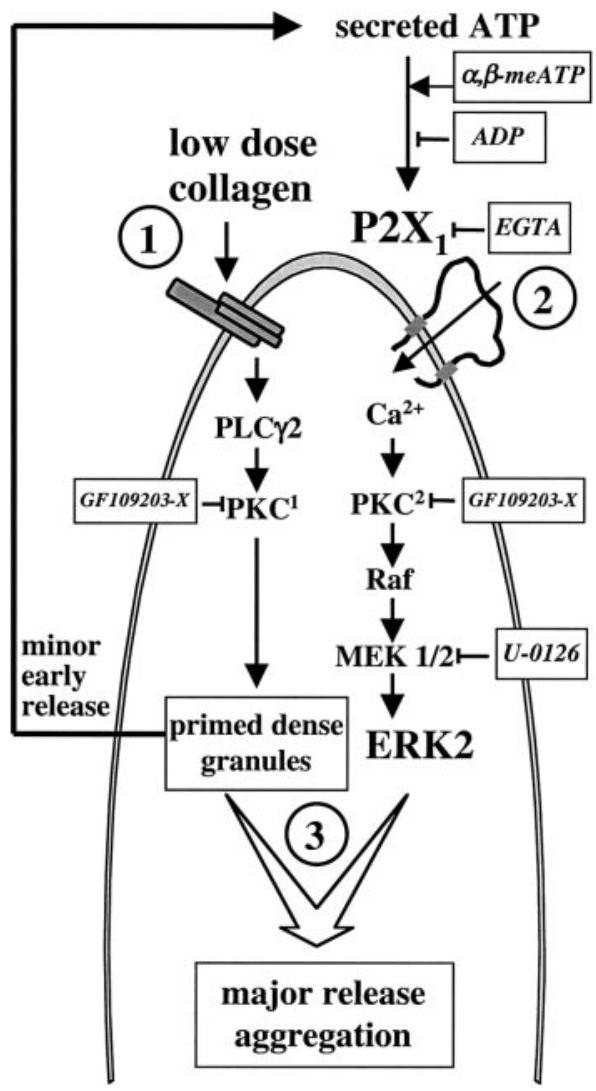

Figure 7. Model depicting the role of $\mathrm{P} 2 \mathrm{X}_{1}$ during platelet activation by low doses of collagen. Platelets stimulated with low doses of collagen (1) rapidly release ATP, which activates a $\mathrm{Ca}^{++}$- and PKC-dependent ERK2 pathway through $\mathrm{P}_{2} \mathrm{X}_{1}$ (2) leading to further granule release and platelet aggregation (3). Both the PKCdependent minor early secretion evoked by collagen and the PKC-dependent P2X 1 -mediated ERK2 activation are inhibited by the PKC inhibitor GF109203-X; these GF109203-X-sensitive PKCs are indicated as PKC1 and PKC2 to refer to their sequential activation during platelet aggregation. The approaches that we used to interfere with the $\mathrm{P}_{2} \mathrm{X}_{1}$-ERK2 pathway at different levels are indicated.

independently of $\mathrm{P} 2 \mathrm{X}_{1}$, and the collagen-induced secretion required to complete platelet aggregation is the result of sequential activation of 2 distinct PKC-dependent pathways (steps 1 and 2).

Our model describes the role of the P2 $\mathrm{X}_{1}$-PKC-ERK2 pathway during platelet activation with low concentrations of collagen. The fact that desensitization of $\mathrm{P}_{2} \mathrm{X}_{1}$ can no longer inhibit the collageninduced ERK2 phosphorylation, ATP secretion, and aggregation when platelets are activated with higher concentrations of collagen implies that ERK can be activated via alternative pathways; because the blockade of the ERK pathway by U-0126 no longer inhibited the collagen-induced platelet aggregation, it appears that ERK activation no longer plays an important role in aggregation under those conditions. Platelet aggregation progressively relies more on the engagement of other activation pathways, such as production of thromboxane and other secreted products.

The inability of HPLC-purified ADP to activate ERK2 is in agreement with a previous study in which ADP was rather linked to p38 MAPK phosphorylation through P2 $\mathrm{Y}_{1} \cdot{ }^{23}$ Because p38 MAPK is not phosphorylated following $\mathrm{P}_{2} \mathrm{X}_{1}$ stimulation (data not shown), it seems that the 2 MAPK pathways, ERK and p38 MAPK, are differentially triggered by ATP and ADP, respectively. Here, the selectivity of the $\mathrm{P} 2 \mathrm{X}_{1}$-ERK2 cascade was further demonstrated in HEK293 cells heterologously expressing $\mathrm{P}_{2} \mathrm{X}_{1}$ or its dominantnegative mutant $\mathrm{P} 2 \mathrm{X}_{1}$ delL. ${ }^{20}$ Indeed, only those cells expressing functional $\mathrm{P} 2 \mathrm{X}_{1}$ channels were able to activate ERKs in response to $\alpha, \beta$-meATP. Therefore, the use of $\mathrm{P}_{2} \mathrm{X}_{1}$ delL allowed us to establish a direct relation between the presence of functional $\mathrm{P}_{2} \mathrm{X}_{1}$ channels in the cell membrane and the activation of the ERK2 signaling pathway.

Despite the biologic significance of secretion for platelet function, the molecular mechanisms governing secretion are only partially understood. ${ }^{24,25}$ Although the ERK pathway has been implicated in secretion processes in other cell types,${ }^{26}$ how ERK activation could be linked to the cellular secretory machinery remains to be investigated. Interestingly, we found that, although $\alpha, \beta$-meATP and collagen are both capable of causing ERK2 phosphorylation, the faster ERK2 phosphorylation elicited by $\alpha, \beta$-meATP is abrogated by simultaneous addition of collagen. Conversely, the collagen-induced ERK2 phosphorylation is disturbed by $\alpha, \beta$-meATP and constitutes the biochemical basis for the inhibition of collagen-induced platelet aggregation, underlying the $\mathrm{P} 2 \mathrm{X}_{1}$ desensitization approach. These findings also emphasize the importance of the kinetics of P2 $\mathrm{X}_{1}$-mediated ERK2 phosphorylation for platelet activation, compatible with a strict necessity to sequentially trigger several components of the platelet secretion machinery (Figure 7).

In other tissues, P2X-type receptors have also been shown to play a role in secretion. Thus, in cardiac sympathetic nerve endings, ATP appeared to induce norepinephrine release by acting at P2X receptors $^{27}$; in the RBA-2 type-2 astrocyte cell line, ATP stimulates $\gamma$-aminobutyric acid (GABA) release through the $\mathrm{P}_{2} \mathrm{X}_{7}$ receptor, PKC, PKA, MEK/ERK, and phospholipase $\mathrm{D}^{28}$; in the guinea pig vas deferens, $\mathrm{P} 2 \mathrm{X}_{1}$ mediates ATP release and contraction ${ }^{29} ; \alpha, \beta$ meATP-sensitive $\mathrm{P} 2 \mathrm{X}$ receptors play a significant role in modulating excitatory sensory synaptic transmission in the spinal cord by enhancing glutamate release. ${ }^{30}$

Our data that the $\mathrm{P} 2 \mathrm{X}_{1}$-activated secretion involves $\mathrm{PKC}$ is in agreement with the study by Yoshioka et $\mathrm{al}^{31}$ who identified PKC $\alpha$ as an essential cytosolic factor for the $\mathrm{Ca}^{++}$-induced secretion from both $\alpha$ and dense granules in platelets. Whether the $\mathrm{Ca}^{++}$ calmodulin-dependent protein cascade, known also to be involved in platelet secretion, ${ }^{32}$ plays a role in the $\mathrm{P} 2 \mathrm{X}_{1}$-activated process, still has to be determined.

In conclusion, we provide evidence for a distinct role of the $\mathrm{P}_{2} \mathrm{X}_{1}$ ion channel in the amplification of platelet granule release initiated by low doses of collagen; this amplification occurs via selective activation of a PKC-dependent ERK2 signaling pathway. These results support the notion that platelet activation by this agonist leads to a concomitant signaling both through the ADP receptors $\mathrm{P}_{2} \mathrm{Y}_{1}$ and $\mathrm{P} 2 \mathrm{Y}_{12}$, and the $\mathrm{ATP}$-gated ion channel $\mathrm{P} 2 \mathrm{X}_{1}$.

\section{References}

1. Reimers H-J. Adenine nucleotides in blood platelets. In: Longenecker GL, ed. The Platelets. Physiology and Pharmacology. Orlando, FL: Academic Press; 1985:85-106.

2. Mills DC. ADP receptors on platelets. Thromb Haemost 1996;76:835-856.
3. Gachet C. ADP receptors of platelets and their inhibition. Thromb Haemost 2001;86:222-232.

4. Hollopeter G, Jantzen H-M, Vincent D, et al. Identification of the platelet ADP receptor targeted by antithrombotic drugs. Nature. 2001; 409:202-207.
5. MacKenzie AB, Mahaut-Smith MP, Sage SO. Activation of receptor-operated cation channels via P2X1 not P2T purinoceptors in human platelets. J Biol Chem. 1996;271:2879-81.

6. Mahaut-Smith MP, Ennion SJ, Rolf MG, Evans $R J . A D P$ is not an agonist at $P 2 X_{1}$ receptors: 
From www.bloodjournal.org by on September 5, 2008. For personal use only.

evidence for separate receptors stimulated by ATP and ADP on human platelets. Br J Pharmacol. 2000;131:108-114.

7. Evans RJ, Lewis C, Buell G, Valera S, North RA, Surprenant A. Pharmacological characterization of heterologously expressed ATP-gated cation channels (P2X purinoceptors). Mol Pharmacol. 1995;48:178-183.

8. Rolf MG, Brearley CA, Mahaut-Smith MP. Platelet shape change evoked by selective activation of P2X ${ }_{1}$ purinoceptors with $\alpha, \beta$-methylene ATP. Thromb Haemost. 2001;85:303-308.

9. Oury C, Toth-Zsamboki E, Thys C, Tytgat J, Vermylen J, Hoylaerts MF. The ATP-gated P2X ${ }_{1}$ ion channel acts as a positive regulator of platelet responses to collagen. Thromb Haemost. 2001; 86:1264-1271.

10. MacKenzie AB, Surprenant A, North RA Functional and molecular diversity of purinergic ion channel receptors. Ann N Y Acad Sci. 1999;868: 716-729.

11. Swanson KD, Reigh C, Landreth GE. ATP-stimulated activation of the mitogen-activated protein kinases through ionotrophic P2X2 purinoreceptors in PC12 cells. difference in purinoreceptor sensitivity in two PC12 cell lines. J Biol Chem. 1998;273:19965-19971.

12. Garrington TP, Johnson GL. Organization and regulation of mitogen-activated protein kinase signaling pathways. Curr Opin Cell Biol. 1999;11: 211-218.

13. Kramer RM, Roberts EF, Hyslop PA, Utterback BG, Hui KY, Jakubowski JA. Differential activation of cytosolic phospholipase A2 (cPLA2) by thrombin and thrombin receptor agonist peptide in human platelets. Evidence for activation of CPLA2 independent of the mitogen-activated protein kinases ERK1/2. J Biol Chem. 1995;270:1481614823.

14. Borsch-Haubold AG, Kramer RM, Watson SP
Inhibition of mitogen-activated protein kinase kinase does not impair primary activation of human platelets. Biochem J. 1996;318:207-212.

15. Aharonovitz $O$, Granot $Y$. Stimulation of mitogenactivated protein kinase and $\mathrm{Na}+/ \mathrm{H}+$ exchanger in human platelets. Differential effect of phorbol ester and vasopressin. J Biol Chem. 1998;271: 16494-16499.

16. Rosado JA, Sage SO. Role of the ERK pathway in the activation of store-mediated calcium entry in human platelets. J Biol Chem. 2001;276: 15659-15665.

17. Nadal F, Lévy-Tolédano S, Grelac F, Caen JP, Rosa J-P, Bryckaert M. Negative regulation of mitogen-activated protein kinase activation by integrin $\alpha_{\| b} \beta_{3}$ in platelets. J Biol Chem. 1997;272: 22381-22384.

18. Li Z, Xi X, Du X. A mitogen-activated protein kinase-dependent signaling pathway in the activation of platelet integrin $\alpha_{11 \mathrm{~b}} \beta_{3}$. J Biol Chem. 2001 276:42226-42232.

19. Ingall $\mathrm{AH}$, Dixon J, Bailey $\mathrm{A}$, et al. Antagonists of the platelet P2T receptor: a novel approach to antithrombotic therapy. J Med Chem. 1999;42: 213-220.

20. Oury C, Toth-Zsamboki E, Van Geet C, et al. A natural dominant negative $\mathrm{P} 2 \mathrm{X} 1$ receptor due to deletion of a single amino acid residue. J Biol Chem. 2000;275:22611-22614.

21. Borsch-Haubold AG, Pasquet S, Watson SP. Direct inhibition of cyclooxygenase- 1 and -2 by the kinase inhibitors SB 203580 and PD 98059 . SB 203580 also inhibits thromboxane synthase. J Biol Chem. 1998;273:28766-28772.

22. Malmgren R. ATP secretion occurs as an initial response in collagen-induced platelet activation. Thromb Res. 1986;43:445-453.

23. Dangelmaier C, Jin J, Daniel JL, Smith JB, Kunapuli SP. The P2Y1 receptor mediates ADP-induced p38 kinase-activating factor generation in human platelets. Eur J Biochem. 2000;267:22832289

24. Polgar J, Reed GL. A critical role for N-ethylmaleimide-sensitive fusion protein (NSF) in platelet granule secretion. Blood. 1999;94:1313-1318.

25. Shirakawa R, Yoshioka A, Horiuchi H, Nishioka $H$ Tabuchi A, Kita T. Small GTPase Rab4 regulates $\mathrm{Ca} 2+-$-induced alpha-granule secretion in platelets. J Biol Chem. 2000;275:33844-33849.

26. Bieger S, Morinville A, Maysinger D. Bisperoxovanadium complex promotes dopamine exocytosis in PC12 cells. Neurochem Int. 2002;40:307314.

27. Sesti C, Broekman MJ, Drosopoulos JH, Islam N Marcus AJ, Levi R. EctoNucleotidase in cardiac sympathetic nerve endings modulates ATP-mediated feedback of norepinephrine release. J Pharmacol Exp Ther. 2002;300:605-611.

28. Wang CM, Chang YY, Kuo JS, Sun SH. Activation of $\mathrm{P} 2 \mathrm{X}(7)$ receptors induced $[(3) \mathrm{H}] \mathrm{GABA}$ release from the RBA-2 type-2 astrocyte cell line through a $\mathrm{Cl}(-) / \mathrm{HCO}(3)(-)$-dependent mechanism. Glia. 2002;37:8-18.

29. Sperlagh B, Illes P, Gerevich Z, Kofalvi A. Distinct mechanisms underlying alpha1-adrenoceptor and $\mathrm{P} 2 \mathrm{x}$ purinoceptor operated ATP release and contraction in the guinea-pig vas deferens. Neurochem Res. 2001;26:951-957.

30. Nakatsuka T, Gu JG. ATP P2X receptor-mediated enhancement of glutamate release and evoked EPSCs in dorsal horn neurons of the rat spinal cord. J Neurosci. 2001;21:6522-6531.

31. Yoshioka A, Shirakawa R, Nishioka H, et al. Identification of protein kinase Calpha as an essential, but not sufficient, cytosolic factor for $\mathrm{Ca} 2+$-induced alpha- and dense-core granule secretion in platelets. J Biol Chem. 2001;276:39379-39385.

32. Nishikawa M, Tanaka T, Hidaka H. $\mathrm{Ca}^{2+}$-calmodulin-dependent phosphorylation and platelet secretion. Nature. 1980;287:863-865. 